\title{
Building A High Customer Experience Management Organization: Towards Customer-Centricity
}

\author{
Lamin B. Ceesay ${ }^{1}$ \\ University of Verona, School of Legal and Economic Sciences, Verona, Italy
}

\begin{abstract}
The dynamics involving market competition and the challenges of dealing with empowered customers, means that creating and delivering relevant customer experience (CX) of service, is as important as creating product or services. Several studies have treated customer experience as though a front-desk, sales-point affair with the customer in the retailing environment, negating the critical role of organization-wide efforts in the overall customer experience management sequence. This review, however, adopts customer-centricity, as a theoretical lens to underscore the [re]configuration of organizational-level factors that are critical to adopting a high customerexperienced centred organization. Based on the review, we highlight conditions for adopting high customer experience management organization: (1) developing an integrated CX strategy, (2) CX-based knowledge management, (3) organizational re-design that supports CX-management, (4) top management commitment, (5) integrated CX IT systems, and (6) CX-oriented HR policies. These practices are only necessary conditions, but not sufficient, for creating, delivering, relevant and sustainable customer experience. However, more robust empirical studies are needed to advance the application of organization-wide customer experience management, which vary across industry, products/services, and sector.
\end{abstract}

Keywords: customer experience; customer-centricity; customer experience design; and integrated customer experience strategy.

DOI: $10.7176 / \mathrm{JMCR} / 71-02$

Publication date:September $30^{\text {th }} 2020$

\section{INTRODUCTION}

The customer experience (henceforth, $\mathrm{CX}$ ) as an emerging concept in Marketing, is gaining popularity in research (e.g. Schmitt and Rogers, 2008; Grewal et al., 2009; Schmitt, 2009; Meyer and Schwager, 2007) and in practice, particularly in the retails sector. Recently, Katherine and Verhoef (2016) considered it as a fast-growing stream of customer-centricity, because of the high potentials in service excellence and customer relationship. For instance, Schmitt and Rogers (2008), describe customer experience as an all-inclusive embodiment of a customer, how he/she behaves, thinks, feels, acts, socializes and senses. Such experiences are personal and subjective, involving the customer at several levels of rational, emotional, sensory, physical, and spiritual levels (Verhoef et al. 2009) which are thus invoked through several phases of interaction between the customer and the brand/services (Lemon and Verhoef, 2016; Verhoef et al. 2009) along the whole purchase journey (including direct contact with the company, it's representative), marketing activities (such as advertising, packaging, ease of use, reliability) (Grundey, 2008; Mayer and Schwager, 2017), product functionality (utilitarian and hedonic values) (Gentile et al., 2007) and the environment in which the experience takes place (Berry et al., 2002) such as the retailing environment (include services encounters, retail atmosphere, time and social influence (Lemon and Verhoef, 2016).

Although several studies reviewed CX based on customer-firm dyads, relating to consumer brand experience, few researchers argue that CX extends far beyond the customer-firm context which is critical to customer overall experience (e.g. Lemon and Verhoef, 2016; Pine and Gilmore, 1998). For instance, designing a customerexperience management centred organization is fundamental to the overall management of customer experience (Meyer and Schwager, 2007). Aligning an organization towards a more customer-centricity is because of the important role of customer satisfaction in organizational performance (Homburg, et al., 2000) and firm's longterm sustainability (Schmitt and Rogers, 2008). This means firms must invest in customer value-seeking behaviour, through effective organizational design, to enhance long-term satisfaction and loyalty.

In fact, some firms don't understand the reasons for CX, and often, resistant to change. However, other corporations are looking to operate divisions to oversee and manage CX. For the former, such resistance could be due to the complexity in the unpredictable nature of customer experience and organizational level alignment of CX (Meyer and Schwager, 2017). Recently, Mosley (2017) suggests that understanding CX requires a shifting emphasis from the transactional CRM to a more relational, holistic focus towards customer total experience. Moreover, we are beginning to see companies adopting managerial roles for managing customer experiences, especially in the information and technology services sectors. This new portfolio of customer experience management could allow for easy co-ordination of inter-functional authority to deliver a superior customer experience (Palmer, 2010). CX as organizational level function could enable customers to enjoy the value they

\footnotetext{
${ }^{1}$ https://orcid.org/0000-0002-5967-7281
} 
seek, to satisfy their needs and expectations, and thus generate a win-win for both customers and the firms (Grewal et al., 2009).

Thus, a comprehensive CX strategy for managing the holistic CX along all the relevant "consumer corridor" is dependent upon the type and form of organization design (Berry et al., 2002; Homburg et al., 2000). Every part of a customer journey is a moment of evaluative reasoning that makeup consumer experience and subsequently consumer behaviour (Gilmore and Pine, 2002). For firms to understand which cues create relevant CX, they should understand what CX really is. Successful brands shape customer's experiences by delivering on the core value propositions (Meyer and Schwager, 2017). For that reason, understanding CX should be atop every manger's priority because time has come when keeping customers is even more important than making sales.

Moreover, studies show that every contact between the customer and the brand, firm or personnel of the firm exhibits series of thought-process resulting to customer impression -both good and bad (Berry et al. 2002; Palmer, 2010). For an overall CX management process, firms must commit resources and expertise on this potential competency -i.e. knowledge of customer experience (Verhoef et al., 2009), and stakeholder participation in CX management process.

Leveraging relevant literature in services marketing, branding and consumer theory, this study tries to discuss the conditions for building a high customer experience organization. Our goal is to address the challenges of adopting CX management by organizations as they look towards a more customer-centricity in today's highly competitive and empowered customers. We hope that our results will advance CX research and highlight the core issues for $\mathrm{CX}$ adoption by mature and emerging firms. The motivation of this literature review is built on the premise that $\mathrm{CX}$ is not only a single encounter between the customer and the firm or the brand as it is popularly seen in a retail environment (e.g. Berry et al., 2002; Meyer and Schwager, 2007; Gilmore and Pine, 2002; Grewal et al., 2009), but one that requires an integrated and organizational re-design towards total CX management. Increasing CX studies in the retailing environment leaves $\mathrm{CX}$ as a function of sales/marketing, in addition to the growing debate, this review maintains that aligning $\mathrm{CX}$ with relevant organizational properties would constitute a more sustainable mean of managing CX. Further, it is of this contention that organizational level commitment to this new but integrated strategy will enhance a unified company-wide design, staging, delivering and communicating memorable and sustainable CX.

The rest of the paper is organized first with the description of strategic CX. Second, we discussed the relevant studies on CX, branding and consumer theory Customer Relationship Management, and services marketing to identify some of the critical organizational level factors for the adoption of CX management organization. The third section entails the discussion and conclusion, highlighting the managerial implication and scientific contribution of the review.

\section{LITERATURE REVIEW}

\subsection{Strategic Customer Experience Management}

Katherine and Verhoef (2016) describe CX management process in terms of designing, measuring and monitoring the total customer experience to promote firm's brand equity in one hand and optimize customer experience on the other hand. Meyer and Schwager (2017) argue that in the heart of customer-centric management is the integration of CX data collection, and assessing within customer-focused IT support group for strategic decision making. CX management is a business strategy designed to manage the $\mathrm{CX}$ through coordination of internal business processes and external marketing and communication agencies (e.g. Berry et al., 2002; Grewal et al., 2009; Mosley, 2007; Verhoef et al., 2009).

Berry, et al., (2002) posit that the first tool in CX management is "customer experience audit," and the subsequent documentation of such body of knowledge for customer-experience centred decision support. Arnould and Price (1993) identify CX management according to four systematic stages of customer experience cycle: (1) pre-consumption experience involving searching for, planning, daydreaming about, foreseeing and imaging the experience; (2) the purchase experience where choice, payment, packaging, and encounter with the services and environment, (3) the core consumption experience level is where sensation, the satiety, the satisfaction/dissatisfaction, the irritation/flow, and transformation and (4) the remember consumption experience and the nostalgic experience - actions a picture to relive an experience. Similarly, Grewal et al., (2009) add five experience moments that are key to sustainable customer satisfaction and loyalty: (1) promotion experience, (2) pricing experience, (3) the merchandising and brand experience, (4) supply chain management experience, and (5) the location. However, the strategic implication for researchers is the ability to measure experience level at any given stage (Walden, 2017).

Integrated management of customer experience could enable firms to acquire distinct and unique competitive advantage (Berry, et al. 2002), because customer-based knowledge allows firms to be more responsive to customer needs than competitors (Skaggs \& Youndt, 2004; Berry et al, 2002). Good experience design allows for stronger ties customers - even in moments of services failure and dissatisfaction (Meyer \& Schwager, 2017). Further, CX designs enable firms to optimize logistic and services ecosystem (Katherine \& Verhoef, 2016). Organizational re- 
design in terms of changes in a firm's priorities, processes and structure is an important starting point to new strategy adoption (Vantrappen and Wirtz, 2018; Mosley, 2007).

New customer strategy could not be successful unless it recognizes employees' experiences (Meyer \& Schwager, 2017). Like all new strategy, CX strategy adoption requires enormous risk and technical research techniques (Palmer, 2010). Technological advances enable newer and better ways to collect, store, and analyses customer-centric information (Shah et al. 2006). One key challenge of CX management is the difficulty involved in its measurement of the multidimensional nature of experience, (Verhoef et al. 2009) and resistance to change among top management executives (Meyer \& Schwager, 2017). Because the global market environments create a higher level of uncertainty, firms are required to adapt to structural change in culture towards a more customercentric approach (Shah et al., 2006). Where managers have an increasing desire to create value, CX could generate increased firm performance and competitiveness (Berry et al., 2002) and through customer involvement in the innovation process (Trejo, et al., 2016). Grewal et al. (2009) argue that a topmost important job for today's managers and CEOs should be about understanding and enhancing strong CX. Further, management commitment shapes the culture of the organization by ensuring every people-management touchpoint is first aligned with the relevant brand ethos of the organization (Mosley, 2007). This allows firms to change their organizational structure to accommodate a more responsive employee's attitude towards customer needs (Humburg et al., 2000; Mosley, 2007).

CX management differs from CRM in that it involves not only the study of all relevant customer-brand touchpoints but the strategic creation of experience providers - as a nudge to create relevant experiences along key customer experience journey (Katherine \& Verhoef, 2016). Most CRM programmes failed due to lack of interfunctional coordinating authority (Palmer, 2010). CX differs from CRM because the former tends to focus more customer relationship and satisfaction rather than current and recorded history of customer experience (Verhoef $e t$ al. 2009). In addition to the CRM programme, CX management could enable firms to leverage this customer-based knowledge as an intellectual integrator of service quality and customer relationship (Palmer, 2010). Based on these studies and other services marketing, branding and CRM literature, we argue that adopting a CX management requires holistic management, driven by an organizational structure that supports the design, and implementation of relevant customer experiences, as illustrated in Fig. 1.

Fig. 1. Integrated customer experience strategy

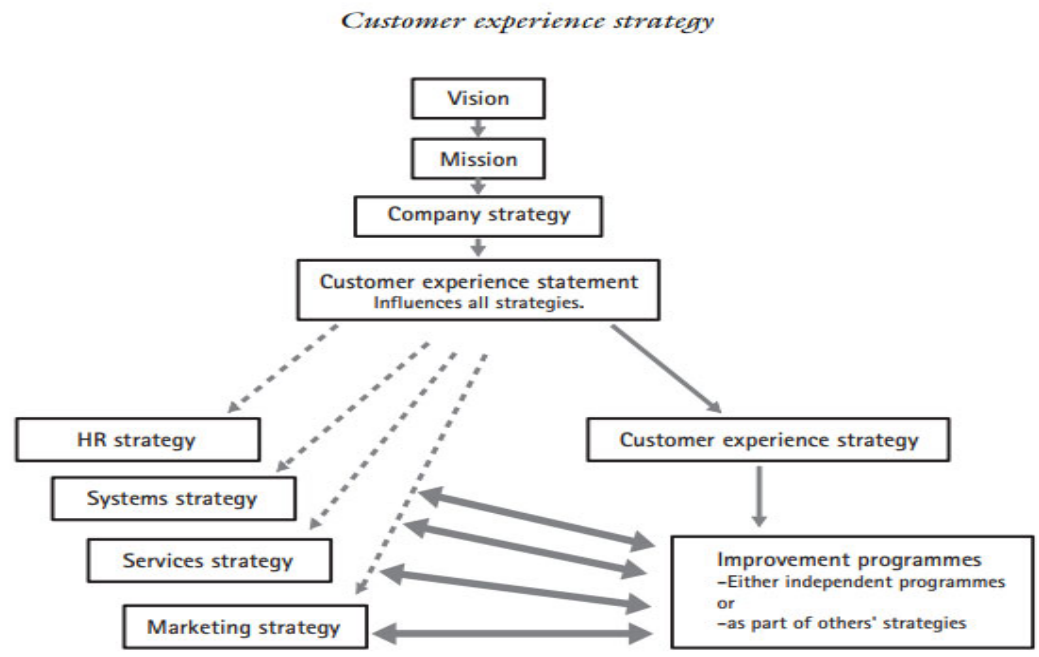

Sourced: Shaw and Ivens, (2005, pp. 197)

\subsection{Organizational level readiness for the Adoption of $\mathrm{CX}$ management}

\subsubsection{Integrated Customer Experience Strategy}

A customer experience strategy represents a firm's pursuit towards a more market-driven, customer experience approach. This effort is more than providing creative products or services. Relevant studies show that today's customers are looking for distinct and memorable experiences in their interactions with the brand, product or services that complement their satisfaction and loyalty (Gilmore and Pine, 2002). Designing a memorable experience lies in the firm's effort towards its overall business and customer strategy (Smith and Joe, 2002). The new customer-base strategy involves the re-configuration of organization in terms of structure, systems, processes, culture, and activities from top management to the lower-level requiring unified effort to CX strategy (Galbraith, 2005). Also, this strategy re-design involves altering organizational structure into the corporate vision to take advantage of new market opportunities (Vantrappen and Wirtz, 2018). Because the business environment is always 
changing, thus the organizational adjustment is necessary to enhance performance.

Therefore compatibility management is key in terms of the firm and its employees' readiness considerations for the adoption of a customer-driven strategy (Verhoef et al., 2009), stakeholder management and company-wide coordination are fundamental (Gummesson, 2008). In the heart of a customer experience-driven strategy, the firm organizational alignment to the customer-driven strategy, cross-functional coordination and up-front leadership commitment and stewardship (Smith and Joe, 2002). Similarly, Customer-driven strategy cannot be realized unless the firm has strong leadership commitment, and ensures all functional units to contribute to customer total experiences (Galbraith, 2005; Smith and Joe, 2002). Customer strategy is a cooperation of relevant functional areas rather than in silos. Moreover, corporate vision and mission must be aligned with the internal culture (Schmitt and Rogers, 2008). Smith and Joe (2002) note that CX strategy requires drafting a CX blueprint that in corporate leadership roles, experience design, and experience management process. Payne and Frow (2006) posit that aligning business and customer experience strategy should be a key priority.

At the heart of CX design are a regular collection of market data on customers, sales, marketing effectiveness and firms responsiveness to market trends (Osarenkhoe and Bennani, 2007).

Since CX business strategy is different from product or services business strategy, specific skills are required to design, to stage and deliver experience (Gilmore and Pine, 2002). CX strategy requires an outward-in approach towards a more customer-focus, market-driven, global in scope and flexibility in a firm's ability to deliver superior value (Osarenkhoe and Bennani, 2007). Therefore, firms must provide sustainable customer by listening to customers and responding to them (Millard, 2006). Two-way communication, consistency, and feedback (Grewal et al., 2009) make a big difference in any customer-centric management. In designing a customer experiencedriven strategy, Smith and Joe (2002) suggest the integration of customers in the entire operations of the firm such that:

1. People are recruited who have an attitude consistent with the brand;

2. Human resources, operations (R\&D, customer service, requisition), and marketing work together and share best practice;

3. Management style reflects the behaviours that would be expected of staff dealing with customers.

In sum, sustainable CX strategy is more customer-driven and requires more inter-functional coordination and designing relevant and memorable experiences throughout the experience journey. This will ensure that all relevant stakeholders enhance customer total experiences. The first point of CX strategy lies in the corporate vision, its leadership commitment to steer the team towards a more customer-centric approach to doing business. The organizational re-configuration and design are a necessary condition of the form's readiness to adopting an integrated customer experience strategy. CX design strategy relies on customer information across all relevant experience point of moments. Although the measurement of customer experience remains highly scared in the extant literature, an integrated CX strategy would provide relevant guides to experience management, control and implementation.

\subsubsection{Customer Experience Management and Organizational Re-design}

Organizational structure determines internal relationship, processes and systems which are important drivers of strategy (Shaw and Ivens, 2000). Aligning CX with organization structure is one that requires [re]configuration of the organization towards a more customer-centricity (Chen and Popovich, 2003; Teixeira et al., 2012). A customercentricity allows firms to be more adapted to customers, and thus internal conversions revolving around what customers need rather than what the organization wants, an outside-in approach (Shaw and Ivens, 2000). This approach enables firms to design products and services as a result of changes in organizational structures, systems, and processes to deliver great customer value (Mascarenhas et al., 2006). These systems and processes enable firms to engage deeply with their customers and consequently design products to install memorable experiences (Pine and Gilmore, 1998). Changing organizational structure that accommodates customer experience moments, will allow for easier management of interaction along relevant customer experience journey. Kumar, et al. (2006) claimed that questions regarding the ownership of the customers in an organization, reside in the organizational structure, systems and processes. Palmer (2010) notes that organizational processes and systems enable the managerial usefulness of customer-driven data for planning and control purposes.

In fact, Shah et al., (2006) argue that key challenges confronting organizations to a more customer-centric, includes, organizational culture, structure, process and financial metrics. To address these challenges, researchers suggest that firms must adopt strong leadership commitment, organizational re-alignment, systems and process supports (Chen and Popovich, 2003; Shah et al., 2006) and revised financial metrics as rewards for employees' customer-centric behaviour (Homburg et al., 2000). Such practices of structural alignment, allows firms to be more culturally responsive to their customers (Homburg et al., (2000). Successful firms leverage the role of organizational culture to promote on-brand customer service behaviour and re-shaping the culture to align corporate brand ethos with employees (Mosley, 2007).

Firms that optimized customer-centricity enjoys long run customer loyalty and profitability (Chen and Popovich, 2003). A great customer relationship with firms is a source of competitive advantage (Walden, 2017). 
The organizations that are customer-centric in approach are known to deliver strong customer value than less customer-oriented firms (Homburg et al., 2000). The transition towards customer-centricity provides firms with an opportunity to create relevant customer-brand experiences (Walden, 2017). Customer-centric structure intentionally use services as the "stage" and products or services as "props" to engage customers in a way that creates memorable events (Pine \& Gilmore, 1997). Mascarenhas et al. (2006) note that integrating total CX and long-term customer loyalty requires an integrated business strategy that revolves within the organizational structure. Such integration facilitates alignment of customers into various stages of service design (Teixeira et al., 2012) and the innovation process (Trejo et al., 2016). Finally, based on these streams of literature, it can be concluded that necessary changes in organizational design in terms of its processes, systems and culture are crucial for the integration of CX management within an organization.

\subsubsection{Customer Experience Management and Leadership Commitment}

The goal of any organization rests on its leadership to be realized. From a common saying, management must give in their blessings to the full realization of any organizational goals, still holds. CX management project is no exception. Management commitment is just more than a CEO giving his blessing to any customer-driven initiative (Chen and Popovich, 2003). The fact is CX can be sustainable when the process involves relevant stakeholders both management, employees, and external agents. Top management commitment is a key starting point to bring the required leadership support (Chen and Popovich, 2003; Schmitt and Rogers, 2008) and innovation to service design and delivery (Trejo et al., 2016).

It lies in top management to resolve disagreement and objections arising from functional areas during customer-driven projects (Chen and Popovich, 2003). Leaders create the right working environment to promote great superior value to customers. They take ownership of the customer-centricity and provide required skills-set for employees (Palmer, 2010) and responsible for integrating CX with the rest of marketing activities and other functional departments (Gilmore and Pine, 2002). Top management must serve as the inter-functional coordinator of CX programs (Chen and Popovich, 2003; Palmer, 2010) to reduce conflict in programs, resources allocation, etc.

Although there are challenges in adopting a change in organizations, it is, however, the Management's affair to effect necessary changes (Chen and Popovich, 2003), and design new strategy and culture that support CX practice (Shaw and Ivens, 2000). Chen and Popovich (2003) suggest that reforms relating to job evaluations, compensation programs, and reward system must reflect positive employee-customer oriented behaviour.

According to Gilmore and Pine (2002), the first level executive responsible for CX in the top management is the Chief Experience Officer (CXO) who should be responsible for developing, launching and managing the rich portfolio of experiences to generate new sources of both revenue and profit. They argue that CXO position should not be assigned to a senior marketing executive officer, because, the skills required to design, scrip and cast experiences differ greatly with those of brands and/or products. Therefore, the best talent is required in the top executive position to lead the team of experienced creators. Lack of the required skills-set for CX on the top management could lead to their weak oversight roles of functional departments and CX activities.

\subsubsection{Customer Experience Management and HR Policies}

Initially, we have seen the affairs of customers to be the sole responsibility of the customer care and salespeople. Today, this is not the case, because, customers are confronted with diverse contact points with the company, and its brands and services. Firms must align their relevant contact points, such as brand value (Schmitt, 2009) and employees as a conjecture to superior customer experience (Shaw and Ivens, 2000). Employees are fundamental integrators to the customers, and their involvement in customer experience efforts of the firm could help in value design and delivery, to enhance the customer experience. Therefore, an integrated HR strategy policy is required to pursue a vigorous customer-centric strategy through recruitment of the right skills set (Shaw and Ivens, 2000), education and training incentives (Chen and Popovich, 2003) and financial metrics for compensation purpose (Shah et al., 2006) towards employees-customer behavior.

Integrating $\mathrm{CX}$ with $\mathrm{HR}$ policies could not only promote desired customer value but also enhance corporate brand integrity (Mosley, 2007). In a retail environment, employees are key experience providers to customers in terms of gesture, body language, comments, dress code and tones of voice, and thus each cue carries with it meaning and expressions that contribute to customers' total experiences (Berry et al, 2002). In fact, Mosley (2007) argues that the absence of employees as priority party, any customer-centric strategy, will likely fail. Thus, employees' participatory tone (Mosley, 2007), clear communication (Chen and Popovich, 2003) and motivated and empowered workforce with the right attitude is fundamental to organization's customer-centricity (Homburg et al., 2000; Mosley, 2007). Studies suggest that successful customer satisfaction is derived from a happy and positively reinforced employee (Berry et al., 2002; Palmer, 2010; Homburg et a.l, 2000). Improving their experiences, positive or negative, is part of the first step to integrating and delivering high-value customer experience.

A plethora of literature support that IT system is fundamental to CRM (e.g. Chen \& Popovich, 2003; Palmer, 2010; 
Kumar et al., 2006; Mascarenhas, et al., 2006, etc.). We have seen a predominant use of technology, and its accompanying solutions, as essential tools in the services design process (Teixeira et al., 2012), an interface for services delivery and customer engagement with products, brands, and the firm (Chen \& Popovich, 2003) and a platform for data generation, analysis, and storage (Grewal et al., 2009).

Studies have acknowledged that customer-driven IT systems provide pool of longitudinal customer data to confront changes in customers' needs through newer and better ways to collect, store, and analyze data for managerial planning and control (Shah et al., 2006; Mascarenhas et al., 2006; Lemon \&Verhoef, 2016).

Leveraging IT systems in marketing enables firms to get even more closer to the marketplace and execute operations that enhance customers' needs efficiently, and gain competitive positions (Zineldin, 1996). Customers are empowered by IT and its related platforms, allowing them to decide which tools they use and when they wish to use them (Shaw and Ivens, 2000). Studies show that firms that leverage IT and organizational change towards a more customer-centricity enjoy customer loyalty and long-run profitability (e.g. Chen and Popovich, 2003; Jayachandran et al., 2005).

Kumar et al. (2006) stress that the success of CRM requires IT that enhances management to grow the value of customer asset. However, IT systems alone are no panacea to marketing problems, unless, they are well harnessed to promote customer value and firm performance. New technologies have become new moments of contact that are crucial throughout the customer experience journey (Lemon and Verhoef, 2016; Shah et al., 2006). Technology and its systems such as the internet, scanners in the supermarkets, mobile phones, and many others are helping to build great customer experiences. These IT systems capture relevant customer data to enable firms during service design and delivery, making IT systems important enablers to customer experience (Shaw and Ivens, 2000; Teixeira et al., 2012). For great CX purposes, firms use IT and its systems, to regularly collect customer data, and to influence customer experience design, delivery process and branding experiences (Mascarenhas et al., 2006; Palmer, 2010).

Customers use IT and online tools to create their own experiences, providing firms with the opportunity to invest in IT to complement experience creation along the customer experience journey (Lemon and Verhoef, 2016). Additionally, this will enable firms to immerse their customers to personalized presentations of their realities or value using the latest technologies (such as Virtual reality, VR). IT systems in this situation will serve as a "stage" and "props" of the desired experience (Gilmore and Pine, 2002). Lemon and Verhoef (2016) find that IT capabilities reduce critical frictions areas such as waiting lines, handling frustrations and indecisions and improve overall retail experiences.

Meyer and Schwager (2007) argue that using IT in CX design allows for the integration of data collection from all relevant interactions, assessing within single, and IT-support customer focus group which help the firm in three major ways: 1) it saves cost, 2) it prevents customers from redundant and annoying solicitation, and 3) it permits comparison of customers based on location, choice of product and many other criteria. These are some of the potentials that integrating CX-IT design systems could foster.

\subsubsection{Customer Experience Knowledge Management}

Customers are key sources of market information, which firms rely on for various value creation purposes. Customer-centred knowledge is a strategic tool for firms that seek to deliver superior customer value (Garrido and Padilla, 2011). Studies demonstrate that customer knowledge asset is a fundamental resource for firms to obtain competitive advantage (e.g. Yali and Taozhen, 2011; Platts and Yeung, 2000) and also allow firms to use such knowledge to orchestrate experience design into a value that meets or exceeds customer's emotional need and expectations (Berry et al., 2002).

The inability to leverage customers as co-creators (prosumers), and innovation-driven members, in new product design and processes (Trejo et al., 2016) rather than as end-users, results in varous in forms of service failure, lack of customer satisfaction (Chinomona, et al., 2013), customer switching (Ceesay, 2017; Ceesay and Sanyang, 2018) and distrust behaviour (Maghzi et al., 2011).

Relevant customer information such as their interest, latent desires and past experiences (Yachin, 2018) does not only enhance firm's innovative capacity but also, allows for a stronger bond between the firm and its customers (García et al., 2016). Furthermore, customer knowledge from lived experiences, are key, in experience design and implementation (Jaziri, 2019). Customers engagement with customers in ways that will motivate them to abandon their positions as customers and assume the role of participants is critical to value design (Mosley, 2007; Yachin, 2018).

Managing experience knowledge requires firms to pay attention to both explicit knowledge, and tacit knowledge, during customer-base decisions making (Platts and Yeung, 2000). Firms leveraging customer-driven information guarantee high innovative performance (García et al., 2016), customer long-term loyalty (Trejo, et al., 2016) and for employees, tacit knowledge can improve individual work efficiency, output and income (Yali and Taozhen, 2011). Jaziri (2019) notes that that managing customer experiential knowledge is a process that enables firms to enhance the future customer service experience, or/and create an offer of service experience, that meets or exceeds customer's lived experience. 
However, Yali and Taozhen (2011) argue that firms must have the ability to learn and transfer this knowledge core competence to harness competitive advantages. Garrido and Padilla (2011) suggest that the importance of integrating knowledge management practices within an organizational structure, processes, organizational members, and internal changes, to enable organization-wide customer-centricity.

In sum, because knowledge is built over time, building on firm-customer interaction, would enhance the understanding of customers beyond their physical characteristics, location and choice. Repeated encounters allow the firm to relate with them at various levels of information, service and problem-solving levels. Each stage, customers demonstrate unique sets of attitudes and emotions, and this knowledge could be used to further enhance satisfaction and lifetime brand experience through sustainable customer experience design and delivery. Thus, investment in CX knowledge area allows for necessary capital, places and equipment for informal organizational activities towards the management of total customer experience (Yali and Taozhen, 2011) within and beyond relevant brand-touch points (Verhoef et al., 2009).

\section{DISCUSSION AND CONCLUSIONS}

\subsection{Discussion}

This section briefly, discuss and highlights some of the theoretical implications in literature. First, our study shares a similar view that organizational re-configuration towards a customer-driven strategy requires changes in organizational structure, systems, and process flows (e.g., Shaw and Ivens, 2000). Such [re]design provides an internal culture towards a more customer-centricity, enabling superior service (Palmer, 2010) and customer brand equity. Harmonizing the internal culture with a customer-centric strategy will provide direction in the adoption of the new business level strategy (Rust et al., 2010). Organizational process and systems enhance the flow of activities and organizational commitment to any new strategic direction. Although, there are no such studies to support the assertion, however, aligning the organizational structure and systems guide the relevant patterns of organizational relationship that provide a realization of CX-driven strategy. This arouses the question for future studies: how organizational designs influence customer-experience culture?

Second, we argue the critical role of the top management in the CX management process in terms of creating a more unifying strategic direction. In fact, Mosley (2007), argues that the absence of strong management buy-in results in lack of sustainable strategic initiative, thus implying that CX-oriented leadership is critical to the CX management. Additionally, strong leadership commitment to strategy allows a unifying direction to attain the firm's goals. Leaders inspire employees and promote a strategy-driven culture. Studies of Chen and Popovich (2003) argue that leadership commitment is more than a CEO's buy-in to a strategy. Thus, leadership that ensures top management discussions and investment in support of a CX management strategy are fundamental. Future studies could explore this debate empirically.

Third, numerous studies are of the view that IT is a crucial tool in CRM (Jayachandran et al., 2005; Chen \& Popovich, 2003; Schmitt \& Rogers, 2008). Our study extends this opinion that a CX-oriented IT system designed to performed several tasks under CX management era: to foster online brand-customer interactivity; to swiftly respond to online service failures; to regularly collect customer-driven data - for CX design, management planning and control (Berry et al., 2002; Shaw \& Ivens, 2000). Customer-focused IT system allows for a more customeroriented decision for experience design and value creation (Palmer, 2010).

Fourth, our study contributes the dialogue by integrating HR policy into the CX management cycle (Chen and Popovich, 2003; Shaw and Ivens, 2000; Shah et al., 2006). We argue that the recruitment of a well-motivated employee with the required skills set to promote the execution of CX strategy is an important aspect of CX-oriented HR policy. Under an atmosphere of well-motivated and energized working condition (Mosley, 2007), CX process thrives. Also, a well-inspired workforce, coupled with skilful employees ensure a well customer-driven to a nurtured customer-driven employee culture.

Fifth, we recognized that an integrated CX strategy is key (Smith and Joe, 2002) arguing that most CX management practices fail because they operate in silos. Marketing and sales alone cannot deliver the desired CX along all relevant customer journey (Vantrappen and Wirtz, 2018), an integrated CX strategy will direct the functional departments towards a more CX centred performances: during R\&D, product and services design, supply chains management, communication, finance, HR, etc. All these areas provide a point of customer experience value (Homburg et al.,2000). 
Fig. 2. Adopting a high customer experience management-oriented organization (author's illustration)

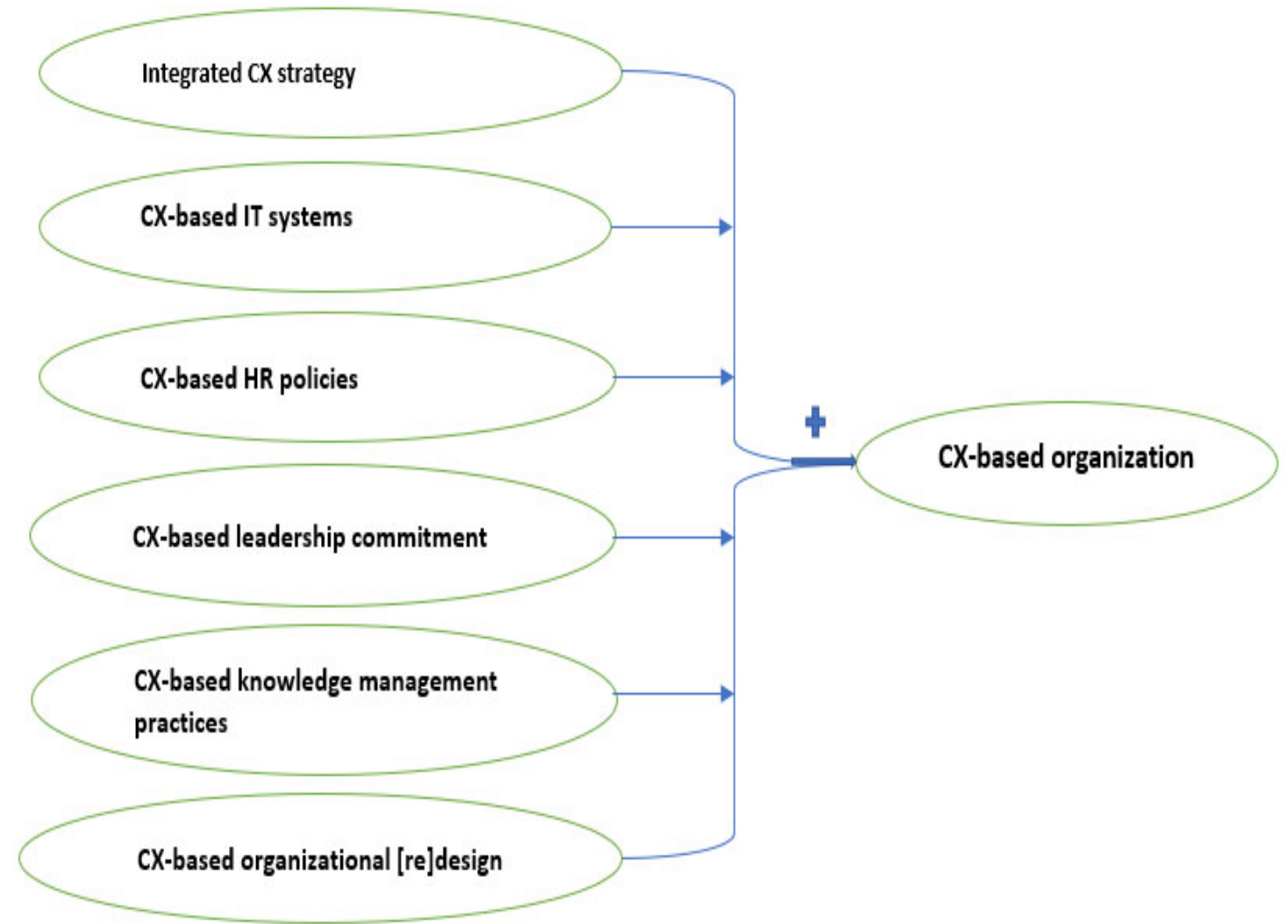

Finally, we advance the CRM theory, adding that when firms understand their customer, they can design relevant experiences to meet their emotional needs and expectations (Jaziri, 2019). According to Trejo et al., (2016), CX knowledge management provides firms with the opportunity to deliver cutting-edge design and customer value. Building on these studies (e.g., Trejo et al., 2016; Jaziri, 2019; Yachin, 2018), knowledge on the customer is as a competitive advantage for firms that leverage this information, consider customers as co-value creators, or key participants in product or service design process. Future studies could explore knowledge management practices, rather than through the lens of customer relationship management, but, through customer experience management. The relationship is subtle, but experiences are deep-seated, and thus influence behaviour in a great way, positive or negative.

\subsection{Conclusion}

The purpose of this review is to identify critical factors for adopting high customer experience management organizational. Results of this review are anticipated to contribute to the emerging discussions of improving service quality beyond the traditional customer services and CRM.

The increasing need for firm's adoption of experiential marketing has been largely due to the proliferation of competition, well-informed and value-driven customer base. To keep up with such pace, firms need to manage customers' overall experience in the value or purchase journey. These efforts are not single interactions between the customer and the firm and its brand, but episodes of moments of contact with customers, to deliver in addition to value, relevant customer experiences. These activities are surmountable, and Marketing and Sales cannot perform this activity alone, but one that requires organization-wide efforts to deliver relevant and sustainable customer experiences.

Despite the relative paucity of the extant literature on CX management adoption, there is a growing popularity of CX in marketing practice, particularly in the retails sector. The CX-driven strategy revolves around the firm's integrated business strategy aim at delivering customer satisfying value at every moment of interaction with the firm and its products and services. The organization-wide support to customer experience management is indeed fundamental, thus firm's readiness for the adoption of CX management is an important starting point to real CX management in practice. Beyond the operational level, sales point $\mathrm{CX}$ practices, the organizational [re]configuration towards a more CX-oriented design is essential in terms of product or services design, creating and staging experience, and delivering a superior experience, are vital to customers' long-term positive cognition about, and the association with the firm and/or products/services (Ceesay, 2017).

This review, however, has limitations, in that the findings are purely theoretical, recognizing the limited 
literature in the field. More empirical studies are required to validate the arguments in the study. Our result is not specific to a particular organization or industry.

\section{REFERENCES}

1. Berry L., L., Lewis P., C. and H. Haeckel, S. (2002) 'Managing the Total Customer Experience', MIT Sloan Management Review. doi: 10.1371/journal.pone.0015090.

2. Ceesay, L. B. (2017) 'Consumer-Brand Association: Determinants of Consumer Bank Switching Intention, Case of the Gambia Retail Banking Sector', Journal of Business \& Financial Affairs, 06(04), pp. 4-11. doi: 10.4172/2167-0234.1000295.

3. Ceesay, L. B. and Sanyang, L. (2018) 'The Impact of Digital Media Advertising on Consumer Behavioral Intention towards Fashion and Luxury Brands : Case of the Gambia', 8(5).

4. Chen, I. J. and Popovich, K. (2003) Understanding customer relationship management (CRM): People, process and technology, Business Process Management Journal. doi: 10.1108/14637150310496758.

5. Chinomona, R., Mahlangu, D. and Pooe, D. (2013) 'Brand Service Quality, Satisfaction, Trust and Preference as Predictors of Consumer Brand Loyalty in the Retailing Industry', Mediterranean Journal of Social Sciences, (November). doi: 10.5901/mjss.2013.v4n14p181.

6. Galbraith, J. R. (2005) 'Designing the Centric: A Guide to Strategy, Structure, and Process'.

7. García, C. and Alejandro C., Romero-Ávila, Diego Usabiaga, C. (2016) 'Análisis PANIC del desempleo español', Trimestre Economico, 83(331), pp. 611-646. doi: 10.1016/j.ijinfomgt.2011.01.002.

8. Garrido, A. and Padilla, A. (2011) 'Analyzing the impact of knowledge management on CRM success: The mediating effects of organizational factors', International Journal of Information Management, pp. 437-444. doi: 10.1016/j.ijinfomgt.2011.01.002.

9. Gilmore, J. H. and Pine, B. J. (2002) 'Customer experience places: The new offering frontier', Strategy \& Leadership, 30(4), pp. 4-11. doi: 10.1108/10878570210435306.

10. Grewal, D., Levy, M. and Kumar, V. (2009) 'Customer Experience Management in Retailing: An Organizing Framework', Journal of Retailing. doi: 10.1016/j.jretai.2009.01.001.

11. Gummesson, E. (2008) 'Customer centricity: Reality or a wild goose chase?', European Business Review, 20(4), pp. 315-330. doi: 10.1108/09555340810886594.

12. Homburg, C., Jr. Workman, J. P. and Jensen, O. (2000) 'Fundamental Changes in Marketing: The Movement Towards a Customer-Focused Organizational Structure', pp. 459-478.

13. Jayachandran, S. et al. (2005) 'The Role of Relational Information Processes and Technology Use in Customer Relationship Management', Journal of Marketing, 69(4), pp. 177-192. doi: 10.1509/jmkg.2005.69.4.177.

14. Jaziri, D. (2019) 'The advent of customer experiential knowledge management approach (CEKM): The integration of offline \& online experiential knowledge', Journal of Business Research. Elsevier, 94(September 2017), pp. 241-256. doi: 10.1016/j.jbusres.2018.05.029.

15. Kumar, V., Lemon, K. N. and Parasuraman, A. (2006) 'Managing customers for value: An overview and research agenda', Journal of Service Research, 9(2), pp. 87-94. doi: 10.1177/1094670506293558.

16. Lemon, K. N. and Verhoef, P. C. (2016) 'Understanding Customer Experience Throughout the Customer Journey', Journal of Marketing, 80(6), pp. 69-96. doi: 10.1509/jm.15.0420.

17. Maghzi, A. et al. (2011) 'Brand Trust in Hotel Industry: Influence of Service Quality and Customer Satisfaction', 2nd International Conference on Business, Economics and Tourism Management, 24, pp. 4246.

18. Mascarenhas, O. A., Kesavan, R. and Bernacchi, M. (2006) 'Lasting customer loyalty: A total customer experience approach', Journal of Consumer Marketing, 23(7), pp. 397-405. doi: 10.1108/07363760610712939.

19. Mejía Trejo, J., Sánchez Gutiérrez, J. and Maldonado Guzman, G. (2016) 'The customer knowledge management and innovation', Contaduria y Administracion, 61(3), pp. 456-477. doi: 10.1016/j.cya.2015.11.011

20. Meyer, C. and Schwager, A. (2007) 'Understanding customer experience [14]', Harvard Business Review, p. 137. doi: $10.1108 / 00242539410067746$.

21. Millard, N. (2006) 'Learning from the "wow" factor - How to engage customers through the design of effective affective customer experiences', BT Technology Journal, 24(1), pp. 11-16. doi: 10.1007/s10550006-0016-y.

22. Mosley, R. W. (2007) 'Customer experience, organisational culture and the employer brand', Journal of Brand Management, 15(2), pp. 123-134.

23. Osarenkhoe, A. and Bennani, A. E. (2007) 'An exploratory study of implementation of customer relationship management strategy', Business Process Management Journal, 13(1), pp. 139-164.

24. Palmer, A. (2010) 'Customer experience management: A critical review of an emerging idea', Journal of 
Services Marketing, 24(3), pp. 196-208.

25. Payne, A. and Frow, P. (2006) 'Customer Relationship Management: from Strategy to Implementation', Journal of Marketing Management, 22(1-2), pp. 135-168. doi: 10.1362/026725706776022272.

26. Pine II, J. B. and Gilmore, J. H. (1998) 'Welcome to the Experience Economy', Harvard Business Review, p. 176 s. doi: Article.

27. Platts, M. J. and Yeung, M. B. (2000) 'Managing learning and tacit', Managing, 355, pp. 347-355.

28. Rust, R. T., Moorman, C. and Gaurav, B. (2010) 'Rethinking Marketing', Harvard Business Review, (February).

29. Schmitt, B. (2009) 'Customer Experience Management', in Customer Experience Management. doi: 10.1007/978-3-8349-8078-6 33.

30. Schmitt, B. H. and Rogers, D. L. (2008) Handbook on Brand and Experience Management.

31. Shah, D. et al. (2006) 'The path to customer centricity', Journal of Service Research, 9(2), pp. 113-124. doi: $10.1177 / 1094670506294666$.

32. Shaw, C. and Ivens, J. (2000) Building Great Customer Experiences, International Journal of Biological Markers. doi: 10.1057/9780230554719.

33. Smith, S. and Joe, W. (2002) Managing the customer experience: Turning customers into advocates, PEARSON EDUCATION LIMITED.

34. Teixeira, J. et al. (2012) 'Customer experience modeling: From customer experience to service design', Journal of Service Management, 23(3), pp. 362-376. doi: 10.1108/09564231211248453.

35. Vantrappen, H. and Wirtz, F. (2018) 'A smarter process for managing and explaining organization design change', Strategy and Leadership, 46(5), pp. 36-43. doi: 10.1108/SL-06-2018-0057.

36. Verhoef, P. C. et al. (2009) 'Customer Experience Creation: Determinants, Dynamics and Management Strategies', Journal of Retailing. doi: 10.1016/j.jretai.2008.11.001.

37. Walden, S. (2017) Customer Experience Management Rebooted: Are you an Experience brand or an Efficiency brand? Palgrave Macmillan. doi: DOI 10.1057/978-1-349-94905-2.

38. Yachin, J. M. (2018) 'The " customer journey": Learning from customers in tourism experience encounters', Tourism Management Perspectives, 28(September), pp. 201-210. doi: 10.1016/j.tmp.2018.09.002.

39. Yali, C. and Taozhen, H. (2011) 'Conceptual model of tacit knowledge transfer within organizations', Proceedings of 2011 International Conference on Product Innovation Management, ICPIM 2011. IEEE, pp. 151-154. doi: 10.1109/ICPIM.2011.5983623.

40. Zineldin, M. (1996) 'Bank strategic positioning and some determinants of bank selection', International Journal of Bank Marketing, 14(6), pp. 12-22. 